\title{
Morphological approach of the sternal foramen: an anatomic study and a short review of the literature
}

\author{
N. Gkantsinikoudis, C. Chaniotakis, G. Gkasdaris, N. Georgiou, S. Kapetanakis \\ Department of Anatomy, Medical School, Democritus University of Thrace, Alexandroupolis, Greece \\ [Received: 18 November 2016; Accepted: 21 December 2016]
}

\begin{abstract}
Background: The sternal foramen (SF) constitutes a specific anatomic defect in sternum, indicating an impaired fusion of ossificated segments, which occurs either in an anatomical part of the sternum or in sternal joints. The aim of this article is to provide baseline statistical data about the variations of the SF, to present a short review of the relevant literature and to compare results with other studies and populations. Materials and methods: We review relevant literature, and we present data obtained from skeletal samples of known population and sex. A total of 35 well-preserved dried sterna from the prefecture of Eastern Macedonia and Thrace, Greece, were selected: 20 men and 15 women with a mean age of $55 \pm 6$ years old. Measurements were made with a sliding calliper and photographic documentation.

Results: The incidence of the SF in the 35 dried specimens was 14.2\%, 4 men (20\% of male sample) and 1 woman (6.6\% of female sample) and $80 \%$ of sternal foramina were observed in male individuals. The SF was found in the sternum body (2 cases, $40 \%$ of foramina), in xiphoid process (2 cases, $40 \%$ of foramina) and in sternoxiphoidal junction (1 case, $20 \%$ of foramina). All of the sterna presented 1 single visible SF. Two anatomically unique cases were identified throughout these 5 sterna, both belonging in male subjects.

Conclusions: The SF constitutes a relatively common variation with great radiological, clinical, and forensic significance. Presence of a SF with irregular bony margins complicates considerably radiological differential diagnosis. Awareness of this important anatomic variation is fundamental for clinicians and autopsy pathologists, in order to avoid severe fatal complications and elucidate the exact cause of death, respectively. (Folia Morphol 2017; 76, 3: 484-490)
\end{abstract}

Key words: sternal, foramen, variations, anatomic study, review

\section{INTRODUCTION}

Sternum is embryologically formed by the fusion of sternal ossification centres located in the manubrium, as well as in the mesosternum. Sternal foramen (SF) represents a congenital anatomic defect, occurring as a result of an impaired and incomplete ossification centre fusion. The first description of the
SF was conducted by Massa in $17^{\text {th }}$ century. Also, Eustachius belongs to the group of pioneers, who noticed and described this important anatomic variation [2].

The presence of a SF has been described several times. The incidence of the SF varies remarkably among different studies in the literature, being reported from $0.06 \%$ up to $18.3 \%[3-5,8,9,12,18-21$, 
$24,26,30]$. Its anatomic localisation is observed in the inferior portion of the sternum and basically in the xiphoid process $[8,13,21,30]$. Pseudoforamen constitutes a rare morphological type of the $\mathrm{SF}$, being described in only 2 studies [11, 30]. The SF usually appears to be a round or oval-shaped orifice with smooth surrounding osseous borders $[6,13,18]$.

The aim of this article is to provide baseline statistical data about the variations of the SF, to present a short review of the relevant literature and to compare results with other studies and populations. Furthermore, we report 2 unique anatomic cases: a foramen with a rare morphological pattern, considerably different from other similar reported cases, as well as a sternum with pseudoforamen in the sternoxiphoidal junction. Clinical and forensic significance of this anatomic variation is shortly discussed.

\section{MATERIALS AND METHODS}

Our study was conducted at the Laboratory of Anatomy, Medical School of Alexandroupolis, Faculty of Health Sciences, Democritus University of Thrace, Alexandroupolis, Greece. The ethics of our study are in accordance with the Greek legislation about ethical standards. These anatomic variations were observed during routine anatomical research. A total of 35 well-preserved dried sterna were measured, 20 men and 15 women with a mean age of $55 \pm 6$ years old. Specimens were from Northern Greece and especially from the prefecture of Eastern Macedonia and Thrace. Five of the sterna featured a single SF, while, in 2 cases, special anatomic characteristics and a rare entity were respectively observed. Only 2 sterna were excluded due to gross morphological malformations.

These unique SF were initially visually examined, so that exact anatomic localisation and periforaminal osseous characteristics could be described. A typical morphological analysis was conducted after visual examination, in order to better identify our findings. For this purpose a digital calliper of $0.01 \mathrm{~mm}$ accuracy was employed (Fig. 1). Photographic documentation and elementary statistical analysis were finally conducted.

\section{RESULTS}

\section{Data analysis}

The incidence of the SF in the 35 dried specimens was $14.2 \%$ (one decimal place approach). SF were observed in 4 men ( $20 \%$ of male sample) and 1 woman ( $6.6 \%$ of female sample) and $80 \%$ of sternal foramina were observed in male individuals.

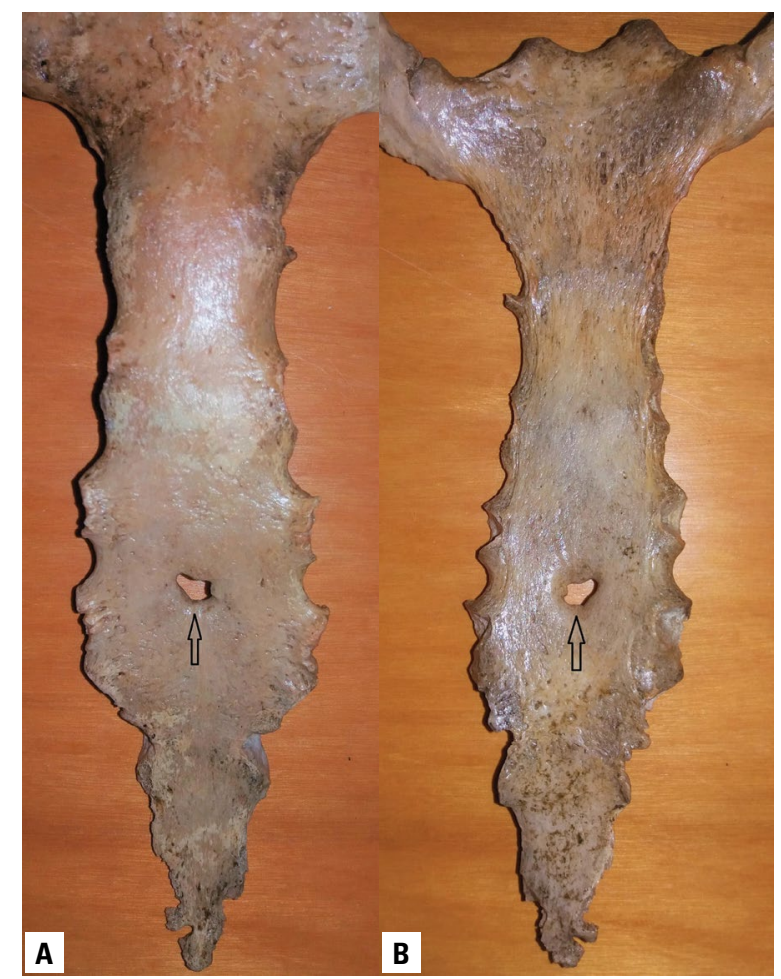

Figure 1. The first case, involving a sternal foramen observed in the sternum body (as indicated with the arrow); A. Anterior view; B. Posterior view.

SFs were found in the sternum body ( 2 cases, $40 \%$ of foramina), in xiphoid process ( 2 cases, $40 \%$ of foramina) and in sternoxiphoidal junction (1 case, $20 \%$ of foramina). All of the sterna presented $1 \mathrm{sin}$ gle visible SF. Two anatomically unique cases were identified throughout these 5 sterna, both belonging in male subjects.

\section{Special cases}

The first case involves a SF in the sternum body. It is located in the midline, at the level of the $4^{\text {th }}$ costal space, with noticeable proximity to the adhesion of $5^{\text {th }}$ costal cartilage (junction of $3^{\text {rd }}$ and $4^{\text {th }}$ sternebrae). The shape of the foramen is roughly ellipsoid, with the superior apex directed superiorly and right to the $4^{\text {th }}$ costal cartilage, and the inferior apex directed inferiorly and left to the $5^{\text {th }}$ costal cartilage adhesion. The inferior bony border is smooth, whereas, concerning the superior bony edge, the right third is smooth and the two left thirds are extremely irregular. This periforaminal irregularity is also observed in the inferior apex, so that the apex obtains a bracket-shape (Fig. 1). Morphometrically, vertical distance of the foramen from the imaginary line connecting the supe- 


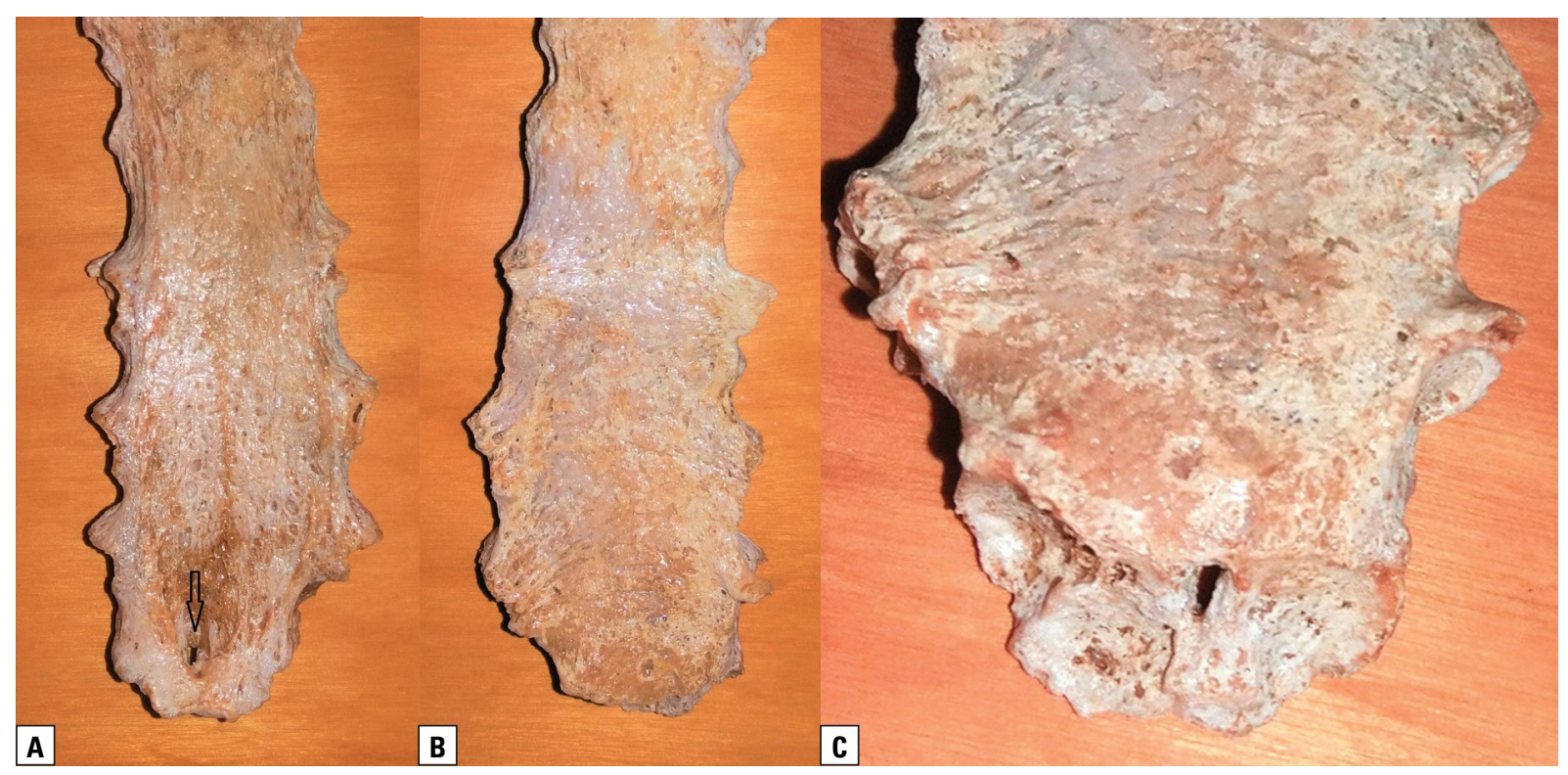

Figure 2. The second case, involving a sternal pseudoforamen observed in the sternoxiphoidal junction (as indicated with the arrow); $\mathbf{A}$. Anterior view; B. Posterior view; C. Bottom-angled view.

rior borders of adherent $5^{\text {th }}$ costal cartilages (junction of $3^{\text {rd }}$ and $4^{\text {th }}$ sternebrae) appears to be minimal. The middle portion of the inferior bony border constitutes a part of this line. Distance of the foramen from the right and left sternal border are measured $17.15 \mathrm{~mm}$ and $18.54 \mathrm{~mm}$, respectively. Vertical diameter of the foramen is measured $5.35 \mathrm{~mm}$, while transverse diameter is $6.05 \mathrm{~mm}$. Maximum diameter of the foramen is $7.09 \mathrm{~mm}$.

The second case involves a sternal pseudoforamen observed in sternoxiphoidal junction. The characteristics of the foramen are observable in the anterior sternal surface. However, the posterior surface lacks of these characteristics, presenting a continuous bony surface along the sternoxiphoidal junction (Fig. 2). The shape of the foramen is, in the anterior view, trapezoidal, with base (right bony border) being vertical to the adhesion of right, and, the other side (left bony border), being vertical to the adhesion of the left $7^{\text {th }}$ costal cartilage. Superior and inferior bony borders are oblique, merging these sides. Periforaminal bony borders are smooth, presenting no irregularities. Morphometrically, distance of the foramen from the right and left sternal border are measured $15.53 \mathrm{~mm}$ and $12.29 \mathrm{~mm}$, respectively. Vertical diameter of the foramen is $3.8 \mathrm{~mm}$ while transverse diameter is measured $1.94 \mathrm{~mm}$.

\section{DISCUSSION}

\section{Anatomy and embryology}

The sternum constitutes the anterior middle portion of the thoracic cage, being anatomically divided in three parts: the manubrium, the body, and the xiphoid process. The manubrium lies superiorly, characterised by the presence of the suprasternal notch in the midline and the clavicular notches laterally. Lateral articulations of the manubrium include articulations with the sternal end of the clavicle via clavicular notches, as well as articulations with the $1^{\text {st }}$ and $2^{\text {nd }}$ costal cartilages via the $1^{\text {st }}$ and superior portion of the $2^{\text {nd }}$ costal notches. Inferiorly, the manubrium articulates with the body of sternum in the manubriosternal joint. The body of the sternum is curved anteriorly and hollow posteriorly, being articulated superiorly with the manubrium (manubriosternal joint), inferiorly with the xiphoid process (sternoxiphoidal joint) and laterally with the $2^{\text {nd }}$ (only inferior portion) to $7^{\text {th }}$ (only superior portion costal cartilages). The xiphoid process constitutes the most distal and short part of the sternum, featuring great amplitude of variations. It is articulated superiorly with body of sternum (sternoxiphoidal joint) and laterally with the inferior portion of $7^{\text {th }}$ costal cartilage [11, 27, 29].

Sternum is embryologically developed from the chondrification of the bilateral sternal plates. The inception of fuse of sternal plates with the ribs is chronologically in $10^{\text {th }}$ week of intrauterine life 
Table 1. Incidence of sternal foramina in the literature

\begin{tabular}{lccc}
\hline Authors (year) & Type of study (specimen) & Sample (sterna) & Percentage of sterna presenting SF \\
\hline McCormick (1981) [19] & Cadaveric & 324 & $7.7 \%$ \\
Cooper et al. (1988) [9] & Radiologic (X-ray) & 2016 & $6.7 \%$ \\
Schratter et al. (1997) [24] & Radiologic (CT) & 100 & $6 \%$ \\
Yekeler et al. (2006) [30] & Radiologic (MDCT) & 1000 & $4.5 \%$ \\
Babinski et al. (2012) [3] & Cadaveric & 180 & $16.6 \%$ \\
El-Busaid et al. (2012) [12] & Anatomic (dry specimens) & 80 & $13.8 \%$ \\
Macaluso and Lucena (2014) [18] & Radiologic (X-ray) & 122 & $3.3 \%$ \\
Bayarogullari et al. (2014) [5] & Radiologic (MDCT) & 250 & $0.06 \%$ \\
Paraskevas et al. (2015) [21] & Anatomic (dry specimens) & 60 & $18.3 \%$ \\
Babinski et al. (2015) [4] & Radiologic (MDCT) & 114 & $10.5 \%$ \\
Boruah et al. (2016) [8] & Radiologic (MDCT) & 1180 & $11.6 \%$ \\
\hline
\end{tabular}

CT — computed tomography, MDCT — multiple detector computed tomography; SF — sternal foramen

placed. Subsequently, sternal bone ossification is accomplished by endochondral ossification, a procedure regulated from specific ossification centres, localised in the manubrium (one ossification point), and, in the mesosternum (three ossification points). Ossification is conducted along specific segments in the mesosternum, known as sternebrae [5]. Sternum is subjected to size and morphologic alterations until $30^{\text {th }}$ year, while segmental fusion may be extended until $25^{\text {th }}$ year of the life $[10,28]$.

Sternal foramina constitute specific anatomic defects in sternum. Their presence indicates an impaired fusion of ossificated segments, occurring theoretically either in an anatomical part of the sternum (i.e. SF in body representing incomplete fusion of adjacent sternebrae), or in sternal joints (manubriosternal or sternoxiphoidal) $[9,21,30]$. However, presence of SF in the manubriosternal junction has not been described.

\section{Incidence and localisation of sternal foramina}

Incidence of SF features great amplitude among the different studies in the literature. Reported data is summarised in Table 1. This amplitude is the result of multiple radiological (with either radiographic or computed tomography [CT] or multiple detector CT [MDCT] evaluation), cadaveric, or anatomic (dry specimens evaluation) studies. Reported incidence ranges from $0.06 \%$ to $18.3 \%$. Prevalence of SF is reported from $0.06 \%$ up to $11.6 \%$ in radiological studies $[4,5,8,18,20,24,26,30], 6.7 \%$ to $16.6 \%$ in cadaveric studies $[3,9,19]$, and $13.8 \%$ and $18.3 \%$ in the 2 published anatomic studies, conducted in dry specimens [12, 21]. SFs were observed in 5 of 35 sterna ( $14.6 \%$ of dried specimens) in the present study. This finding is in agreement with the results of the other 2 anatomic studies, with our percentage being between the reported in the latter studies. Prevalence of SF is reported under $11.3 \%$ in all radiological and 2 of the 3 cadaveric studies. The higher incidence reported in anatomic studies (and in the last cadaveric) could be attributed to the small sample utilised.

Prevalence of SF features an important correlation with the sex, being reported mainly in male subjects among the studies $[8,18,25]$. SF may be even only in males encountered [18]. Most recent data indicate a male:female ratio $2.5: 1$ among the subjects featuring a SF [8]. In our study this ratio was measured 4:1.

Anatomic localisation of the SF is variable (Fig. 3 ). $\mathrm{SF}$ is basically observed in midline, in the lower third of sternum. Xiphoidal foramen constitutes the most common type of sternal foramen and, concerning SF in body, it is fundamentally observed in $5^{\text {th }}$ intercostal segment $[8,11,13,21,30]$. However, prevalence of SF in body is reported to be higher than this in xiphoid process in specific studies $[5,12]$. In our study, SFs were, in $60 \%$ of the sterna with SF, in xiphoid process, while, in $40 \%$, in the body of the sternum detected. Our data are in agreement with the other studies, as can be confirmed in Table 2 .

\section{Case analysis and radiological impact}

Concerning the first case, originality is identified in the periforaminal osseous characteristics. Morphometric characteristics of the $\mathrm{SF}$, are, despite their great variability in localisation, impressively similar. SF is 


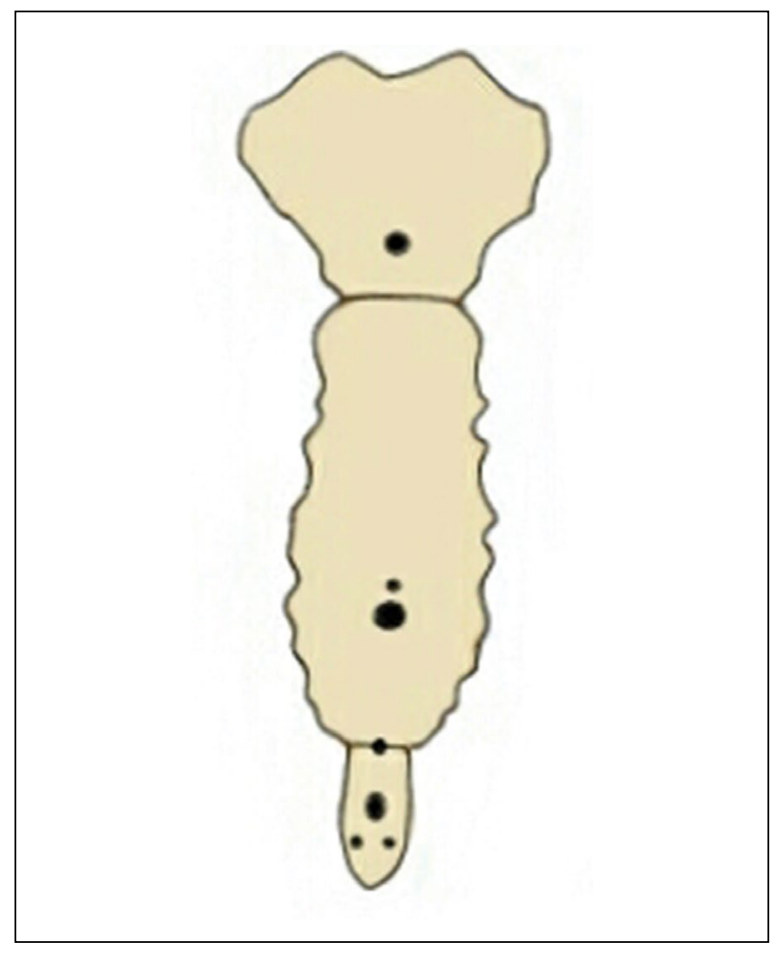

Figure 3. Anatomic localisation of the variations of the sternal foramen.

typically described as a round or oval-shaped defect with smooth periforaminal edges $[6,18]$. Dimensions of the foramen are in average $6 \mathrm{~mm}$. However, in this case, the observed irregularity is in complete contrast to the classical description of a SF. It has been reported that SF may occasionally mimic lytic lesions, appearing as a focal defect with photopoenia $[11,17]$. These lytic lesions may present secondary to infections or represent either primary neoplastic lesions or metastatic foci. In any case, these lesions are anatomically and radiologically characterized by irregular margins [11].

To our best knowledge, this is the first description of a SF with irregular bony margins and abnormal shape. This characteristic, if present, may considerably complicate radiological differential diagnosis of SF between lytic lesions, characterised therefore by great radiological significance. In this case, determination of this lesion with cross sectional imaging may not possibly be accomplished, since radiological characteristics of SF and lytic lesions present remarkable similarity. Radiologists and clinicians should be therefore aware of this special type of foramen, in order to avoid misdiagnosis. Radiological presence of a lesion with the analysed characteristics may constitute a congenital
Table 2. Comparative foraminal localisation in sternum

\begin{tabular}{lcc}
\hline Authors (year) & \multicolumn{2}{c}{ Localisation of foramen } \\
\cline { 2 - 3 } & Sternal body & Xiphoid process \\
\hline Yekeler et al. (2006) [30] & $4.5 \%$ & $27.4 \%$ \\
El-Busaid et al. (2012) [12] & $11.3 \%$ & $4.5 \%$ \\
Paraskevas et al. (2015) [21] & $5 \%$ & $11.3 \%$ \\
\hline
\end{tabular}

Table 3. Special reported cases of sternal foramina

\begin{tabular}{lc}
\hline Authors (year) & $\begin{array}{c}\text { Special case described } \\
\text { (regarding single sterna) }\end{array}$ \\
\hline Cooper et al. (1988) [9] & Manubrial foramen \\
Yekeler et al. (2006) [30] & Pseudoforamen \\
Akin et al. (2011) [1] & Two or more xiphoidal foramina \\
Paraskevas et al. (2015) [21] & Multiple xiphoidal foramina \\
Duraikannu et al. (2016) [11] & $\begin{array}{c}\text { 1. Multiple foramina in sternal } \\
\text { body and xiphoid process }\end{array}$ \\
& $\begin{array}{c}\text { 2. Large foramen measuring 11 mm } \\
\text { 3. Pseudoforamina }\end{array}$ \\
Paraskevas et al. (2016) [22] & $\begin{array}{c}\text { Two sternal foramina of undocumented } \\
\text { size (body and xiphoid process) }\end{array}$ \\
\hline
\end{tabular}

SF and not necessarily a lytic lesion. The case of a congenital sternal foramen should be radiologically hypothesized and included in differential diagnosis.

On the other side, the second case involves a pseudoforamen located in sternoxiphoidal junction. Prevalence of the sternal pseudoforamen (a special and autonomically described of SF) in the sternoxiphoidal junction has been only two times reported, being $0.01 \%$ and $3.3 \%$ [30]. In addition, this rare type of foramen has been described as a special case in another study [11]. In our study, prevalence of pseudoforamen was $2.8 \%$, a percentage between the other two studies, despite the small sample used.

Except for the reported, SF feature an even greater range in terms of their coexistence and size. Reported special anatomic variations concerning SF are summarized in Table 3. Diameters of foramina as measured among the different studies are mentioned in Table 4.

\section{Clinical and forensic significance}

Sternal foramen constitutes asymptomatic congenital defects, which can be manifested only by CT $[13,23]$. This characteristic constitutes a fundamental parameter, with which clinicians should be familiar. Gossner [15] studied the anatomic relationship of SF 
Table 4. Diameters of foramina as measured among the different studies (one decimal place approach)

\begin{tabular}{|c|c|c|}
\hline \multirow[t]{2}{*}{ Authors (year) } & \multicolumn{2}{|c|}{ Foraminal diameters $[\mathrm{mm}]$ — diametrical range (mean) } \\
\hline & Vertical diameter & Transverse diameter \\
\hline McCormick (1981) [19] & \multicolumn{2}{|c|}{ 3-18 (mean not reported) } \\
\hline Cooper et al. (1988) [9] & \multicolumn{2}{|c|}{ 3-10 (mean not reported) } \\
\hline Schratter et al. (1997) [24] & \multicolumn{2}{|c|}{$3-12(6)$} \\
\hline Yekeler et al. (2006) [30] & \multicolumn{2}{|c|}{$2-16(6.5)$} \\
\hline Babinski et al. (2012) [3] & $4-7(5.5)$ & $3-6.5(4.5)$ \\
\hline El-Busaid et al. (2012) [12] & \multicolumn{2}{|c|}{ No specific information reported } \\
\hline Macaluso and Lucena (2014) [18] & \multicolumn{2}{|c|}{ No specific information reported } \\
\hline Bayarogullari et al. (2014) [5] & \multicolumn{2}{|c|}{ No specific information reported } \\
\hline Paraskevas et al. (2015) [21] & $1-16.7(4.4)$ & $0.9-8.6(3.4)$ \\
\hline Babinski et al. (2015) [4] & \multicolumn{2}{|c|}{$3-16(5.5)$} \\
\hline Boruah et al. (2016) [8] & $1.6-18.6(6.7)$ & $1.3-15.1(5.8)$ \\
\hline Present study & $2.3-8.1(5.1)$ & $1.1-6.2(4.8)$ \\
\hline
\end{tabular}

to intrathoracic structures in 15 patients, reporting that lung parenchyma constituted the adjacent structure in the majority of patients (53.3\%) presenting SF. Mediastinal fat featured secondarily remarkable proximity to SF (33.3\%), while, heart was the adjacent anatomical structure in only $20 \%$ of patients. In absolute contrast to these results, Boruah et al. [8] reported that, in 137 patients presenting SF, directly adjacent anatomical structure was fundamentally mediastinal fat (53.5\%), secondarily anterior pericardium (32.1\%) and, only in $14.6 \%$ of patients, lung parenchyma.

Cases of fatal cardiac tamponade due to acupuncture or sternal marrow aspiration have been satisfactorily described in the literature [7, 11, 16]. Nevertheless, provocation of pneumothorax has not been described. Consequently, perforation of cardiac vessels, or, in case of deeper insertion of the needle, of pericardium, large thoracic vessels and right ventricle seem to constitute major risks in bone marrow aspiration or acupuncture, in case of presence of sternal foramen $[13,21]$. Sternal marrow puncture should therefore be under strict precautionary measures conducted. Needle insertion in the upper two thirds of sternal body and radiologic contribution preoperatively and during aspiration (CT-guidance) are recommended, in order to minimize the severe life-threating complications [12, 15, 23]. In terms of acupuncture, entry point CV-17, also known as Shazong, is anatomically located in the midline, at the transverse levels of nipples. Avoidance of needle vertical insertion in this point is necessary [8].
Possible presence of SF may even complicate forensic investigation [14]. Forensic investigation could be misled by misinterpretation of presented SF as bullet (entry point) or other traumatic penetrating injury. Proper forensic evaluation is essential particularly in cases of suicide and homicide, so that exact cause of death can be determined $[8,21]$. In terms of anthropology, antemortem radiologic evaluation of victim, included in medical record, can fundamentally contribute in identification [21].

\section{CONCLUSIONS}

Sternal foramen constitutes relatively common variation with great radiological, clinical, and forensic significance. Incidence in this study was encountered $14.2 \%$. Presence of a SF with irregular bony margins complicates considerably radiological differential diagnosis, since SF may rarely feature these characteristics. Awareness of this important anatomic variation is fundamental for clinicians and autopsy pathologists, in order to avoid severe fatal complications and elucidate the exact cause of death, respectively.

\section{REFERENCES}

1. Akin $\mathrm{K}$, Kosehan D, Topcu A, et al. Anatomic evaluation of the xiphoid process with 64-row multidetector computed tomography. Skeletal Radiol. 2011; 40(4): 447-452, doi: 10.1007/ s00256-010-1022-1, indexed in Pubmed: 20721551.

2. Ashley GT. The relationship between the pattern of ossification and the definitive shape of the mesosternum in man. J Anat. 1956; 90(1): 87-105, indexed in Pubmed: 13295154. 
3. Babinski M, Rafael F, Steil A, et al. High prevalence of sternal foramen: quantitative, anatomical analysis and its clinical implications in acupuncture practice. Int J Morphol. 2012; 30(3): 1042-1049, doi: 10.4067/s071795022012000300045.

4. Babinski MA, de Lemos L, Babinski MSD, et al. Frequency of sternal foramen evaluated by MDCT: a minor variation of great relevance. Surg Radiol Anat. 2015; 37(3): 287-291, doi: 10.1007/s00276-014-1339-x, indexed in Pubmed: 25023390

5. Bayaroğulları H, Yengil E, Davran R, et al. Evaluation of the postnatal development of the sternum and sternal variations using multidetector CT. Diagn Interv Radiol. 2014; 20(1): 82-89, doi: 10.5152/dir.2013.13121, indexed in Pubmed: 24100061.

6. Bermio VS, Jos Hemalatha GA. Congenital foramen in the body of sternum. Int J Anat Res. 2014; 2(3): 545-548.

7. Bhootra BL. Fatality following a sternal bone marrow aspiration procedure: a case report. Med Sci Law. 2004; 44(2): 170-172, doi: 10.1258/rsmmsl.44.2.170, indexed in Pubmed: 15176631.

8. Boruah DK, Prakash A, Yadav RR, et al. The safe zone for blinded sternal interventions based on CT evaluation of midline congenital sternal foramina. Skeletal Radiol. 2016; 45(12): 1619-1628, doi: 10.1007/s00256-016-2473-9, indexed in Pubmed: 27629288.

9. Cooper PD, Stewart JH, McCormick WF. Development and morphology of the sternal foramen. Am J Forensic Med Pathol. 1988; 9(4): 342-347, indexed in Pubmed: 3239556.

10. Cubuk S, Hamcan S. Anatomic variations of sternum may mimic traumatic complications. Am J Emerg Med. 2016; 34(9): 1912.e1-1912.e2, doi: 10.1016/j. ajem.2016.01.026, indexed in Pubmed: 26905807.

11. Duraikannu C, Noronha OV, Sundarrajan P. MDCT evaluation of sternal variations: Pictorial essay. Indian J Radiol Imaging. 2016; 26(2): 185-194, doi: 10.4103/09713026.184407, indexed in Pubmed: 27413263.

12. El-Busaid H, Kaisha W, Hassanali J, et al. Sternal foramina and variant xiphoid morphology in a Kenyan population. Folia Morphol. 2012; 71(1): 19-22, indexed in Pubmed: 22532180.

13. Fokin AA. Cleft sternum and sternal foramen. Chest Surg Clin N Am. 2000; 10(2): 261-276, indexed in Pubmed: 10803333.

14. Fokin AA. Thoracic defects: cleft sternum and Poland syndrome. Thorac Surg Clin. 2010; 20(4): 575-582, doi: 10.1016/j.thorsurg.2010.06.001, indexed in Pubmed: 20974442.

15. Gossner J. Relationship of sternal foramina to vital structures of the chest: a computed tomographic study. Anat Res Int. 2013; 2013: 780193, doi: 10.1155/2013/780193, indexed in Pubmed: 24224092.

16. Halvorsen TB, Anda SS, Naess AB, et al. Fatal cardiac tamponade after acupuncture through congenital sternal foramen. Lancet. 1995; 345(8958): 1175, indexed in Pubmed: 7723561.

17. Ishii S, Shishido F, Miyajima M, et al. Causes of photopenic defects in the lower sternum on bone scintigraphy and correlation with multidetector CT. Clin Nucl Med. 2011; 36(5): 355-358, doi: 10.1097/RLU.0b013e31820aa41b, indexed in Pubmed: 21467851.

18. Macaluso PJ, Lucena J. Morphological variations of the anterior thoracic skeleton and their forensic significance: radiographic findings in a Spanish autopsy sample. Forensic Sci Int. 2014; 241: 220.e1-220.e7, doi: 10.1016/j.forsciint.2014.05.009, indexed in Pubmed: 24933632.

19. McCormick WF. Sternal foramena in man. Am J Forensic Med Pathol. 1981; 2(3): 249-252, indexed in Pubmed: 7325136.

20. Moore MK, Stewart JH, McCormick WF. Anomalies of the human chest plate area. Radiographic findings in a large autopsy population. Am J Forensic Med Pathol. 1988; 9(4): 348-354, indexed in Pubmed: 3239557.

21. Paraskevas G, Tzika M, Anastasopoulos N, et al. Sternal foramina: incidence in Greek population, anatomy and clinical considerations. Surg Radiol Anat. 2015; 37(7): 845-851, doi: 10.1007/s00276-014-1412-5, indexed in Pubmed: 25552238.

22. Paraskevas GK, Tzika M, Natsis K. Double sternal foramina in a dried sternum: a rare normal variant and its radiologic assessment. Surg Radiol Anat. 2016; 38(8): 991-993, doi: 10.1007/s00276-016-1663-4, indexed in Pubmed: 26988088.

23. Pevenage $P$, De Maeseneer, $M$, Muylle $K$, et al. Sternal foramen simulating osteolytic lesion on scintigraphy and SPET imaging. Ann Nucl Med Sci. 2002; 15(4): 227-230.

24. Schratter M, Bijak M, Nissel $H$, et al. [The foramen sternale: a minor anomaly -- great relevance]. Rofo. 1997; 166(1): 69-71, doi: 10.1055/s-2007-1015380, indexed in Pubmed: 9072108.

25. Singh J, Pathak RK. Sex and age related non-metric variation of the human sternum in a Northwest Indian postmortem sample: a pilot study. Forensic Sci Int. 2013; 228(1-3): 181.e1-181.12, doi: 10.1016/j.forsciint.2013.02.002, indexed in Pubmed: 23453187.

26. Stark P. Midline sternal foramen: $C T$ demonstration. J Comput Assist Tomogr. 1985; 9(3): 489-490, indexed in Pubmed: 3989043.

27. Uzun C, Atman ED, Ustuner E, et al. Surface anatomy and anatomical planes in the adult turkish population. Clin Anat. 2016; 29(2): 183-190, doi: 10.1002/ca.22634, indexed in Pubmed: 26403267.

28. Weaver AA, Schoell SL, Nguyen CM, et al. Morphometric analysis of variation in the sternum with sex and age. J Morphol. 2014; 275(11): 1284-1299, doi: 10.1002/ jmor.20302, indexed in Pubmed: 24935890.

29. Xie YZ, Wang BJ, Yun JS, et al. Morphology of the human xiphoid process: dissection and radiography of cadavers and MDCT of patients. Surg Radiol Anat. 2014; 36(3): 209-217, doi: 10.1007/s00276-013-1163-8, indexed in Pubmed: 23839070.

30. Yekeler E, Tunaci M, Tunaci A, et al. Frequency of sternal variations and anomalies evaluated by MDCT. AJR Am J Roentgenol. 2006; 186(4): 956-960, doi: 10.2214/ AJR.04.1779, indexed in Pubmed: 16554563. 